\title{
Economic valuation of an offshore wind farm in Greece: the role of individual's base-state influences and beliefs in the value formation process
}

Article

Accepted Version

Georgiou, I. and Areal, F. J. (2015) Economic valuation of an offshore wind farm in Greece: the role of individual's basestate influences and beliefs in the value formation process. Renewable \& Sustainable Energy Reviews, 52. pp. 717-724. ISSN 1364-0321 doi:

https://doi.org/10.1016/j.rser.2015.07.178 Available at https://centaur.reading.ac.uk/40912/

It is advisable to refer to the publisher's version if you intend to cite from the work. See Guidance on citing.

To link to this article DOI: http://dx.doi.org/10.1016/j.rser.2015.07.178

Publisher: Elsevier

All outputs in CentAUR are protected by Intellectual Property Rights law, including copyright law. Copyright and IPR is retained by the creators or other copyright holders. Terms and conditions for use of this material are defined in the End User Agreement. 


\section{www.reading.ac.uk/centaur}

\section{CentAUR}

Central Archive at the University of Reading

Reading's research outputs online 
Economic valuation of an offshore wind farm in Greece: The role of individual's basestate influences and beliefs in the value formation process

Isabella Georgiou; Francisco J. Areal*

School of Agriculture, Policy and Development, University of Reading, Reading, UK

*Correspondence concerning this article should be addressed to Dr. Francisco Areal, Department of Agricultural and Food Economics, The University of Reading, Earley Gate, PO Box 236, Reading, RG6 6AR, email: f.j.areal@,reading.ac.uk, phone $+44(0) 1183788970$ 


\begin{abstract}
The increased concern for the impacts of climate change on the environment, along with the growing industry of renewable energy sources, and especially wind power, has made the valuation of environmental services and goods of great significance. Offshore wind energy is being exploited exponentially and its importance for renewable energy generation is increasing. We apply a double-bound dichotomous Contingent Valuation Method analysis in order to both a) estimating the Willingness to Pay (WTP) of Greek residents for green electricity produced by offshore wind farm located between the islands of Tinos and Andros and $b$ ) identifying factors behind respondents' WTP including individual's behaviour toward environment and individual's views on climate change and renewable energy. A total of 141 respondents participated in the questionnaire. Results show that the respondents are willing to pay on average $20 €$ every two months through their electricity bill in return for carbon-free electricity and water saving from the wind farm. Respondents' environmental consciousness and their perception towards climate change and renewable energy have a positive effect on their WTP.

Key words: willingness to pay; offshore wind farm; base-state influences' base-state beliefs
\end{abstract}

\title{
1. Introduction
}

Although technological advances in renewable energy continue to contribute to reducing Greenhouse Gas (GHG) emissions, total energy consumption has also continued to increase during last decades being fossil fuels the major source of energy (Figure 1). Hence, the associated impacts of GHG emissions on the environment are still a major concern for achieving sustainability $[1,2]$.

Figure 1. 


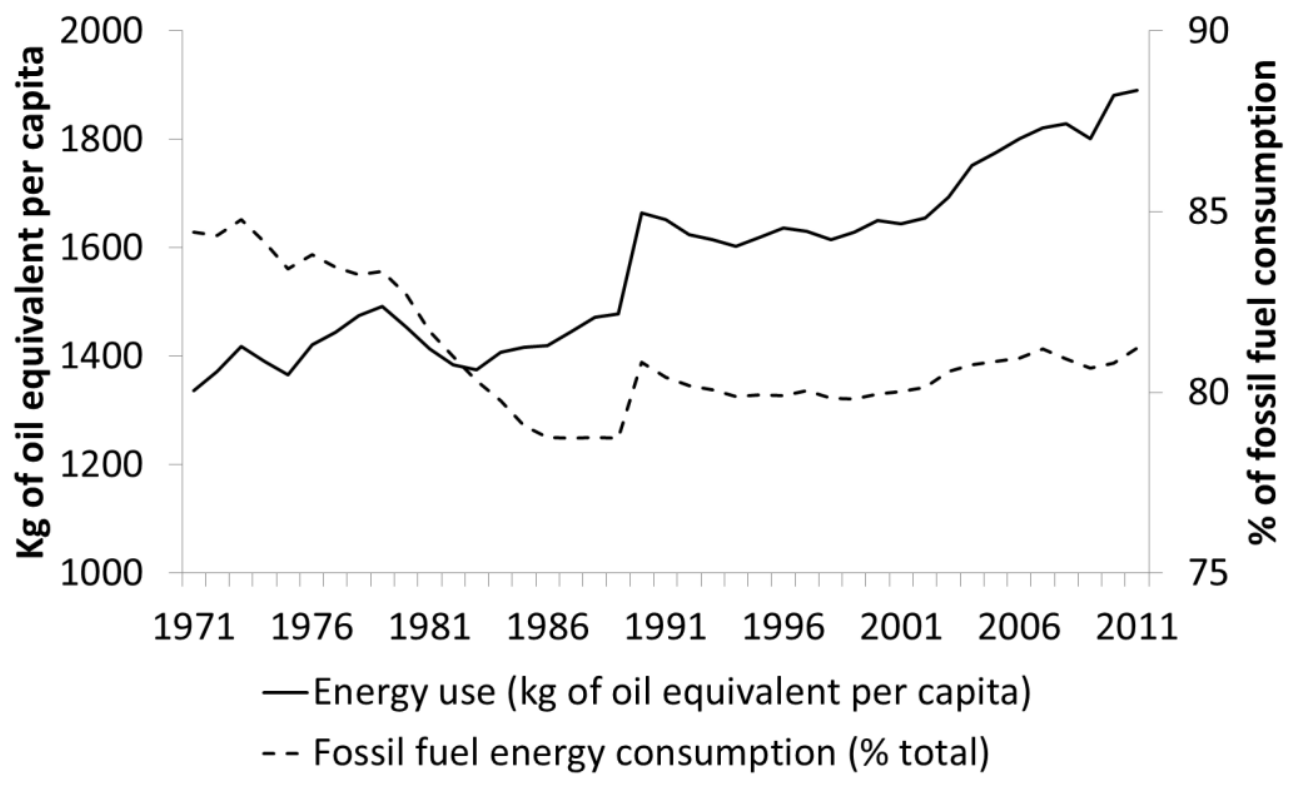

Source: World Bank data (http://data.worldbank.org/topic/energy-and-mining)

\subsection{Wind farms and climate change mitigation}

The development of green energy sources such as wind farms plays an important role on mitigating the effects of climate change. The European Union has supported and promoted the development of the renewable energy sector, setting targets for its member-states. According to the 20-20-20 goals set by the European Council in 2007, by 2020 the EU member-states must reduce the GHG emissions by $20 \%$, increase the share of renewable energy by $20 \%$ and improve energy efficiency by $20 \%$. Moreover, the EU Directive 2009/28/EC establishes that the share of energy from renewables for each member-state would be based on each member state's potential, its energy mix and would be calculated according to the gross energy consumption from Renewable Energy Sources (RES) of each state. In 2012 Greece's renewable energy share accounted for the $15.1 \%$ of the total gross final energy consumption, while the EU's 2020 target for Greece is estimated to be 18\% [3]. Currently, in Greece, most of the renewable energy power generated is derived from wind power (75\%), followed by solar power [4]. Furthermore, Greece has declared that by 2020, 40\% of its gross electrical energy demand will be supplied by electrical energy production derived from renewable energy sources, and $50 \%$ of this from wind power [5]. 
Due to its nature wind energy production is difficult to predict and its energy generation is neither constant nor stable $[6,7]$. Despite such difficulties associated with its predictability and instability of wind energy generation, wind energy is one of the fastest growing energy industries with the EU having a leading role having a capacity of covering $8 \%$ of the EU's total energy demand from wind power $[8,9]$. Two types of wind power can be distinguished according to the location of the wind power installation: onshore, if the installation is located in mainland areas and offshore if installations are located in the sea, away from the coast. On January 2015 there were a total of 2,488 offshore wind turbines installed and grid connected in 74 wind farms in 11 countries in Europe with a combined capacity of 8,045 MW [10] (Figure 2). The industry expects reaching $10 \mathrm{GW}$ by 2015 [11]. Further in the future the European Wind Energy Association (EWEA) has identified 26.4 GW of consented offshore wind farms in Europe and future plans for offshore wind farms totalling more than $98 \mathrm{GW}$, $0.71 \mathrm{GW}$ in Greece [11]. The estimated available offshore area available in Greece is over $30,000 \mathrm{~km}^{2}$ with an unrestricted technical potential ${ }^{1}$ for offshore wind energy in 2030 Greece of approximately 100,000 MW and for all EU countries 3,400,000 MW [12]. Offshore wind production in Greece is a relatively new and highly growing industry with the number of offshore wind farms constantly increasing due to the fact that over $70 \%$ of the maritime areas in Greece have a significant wind capacity [12]. It is worth mention that recently it has been pointed out that climate change itself may affect winds too becoming an important factor to take into account when planning locations to develop wind farms [13]. Since wind speeds are sensitive to climate variability, wind speeds will increase in some areas and decrease in other areas. Hence, whereas there will be areas where the expansion of wind energy installed will become favourable other areas or current installations may become less productively attractive.

\footnotetext{
${ }^{1}$ This does not take into account other uses of the sea area (e.g. shipping routes, military use of offshore areas, oil and gas exploration, and tourist zones), which may limit the potential for offshore wind developments.
} 
Figure 2. Annual and cumulative off-shore wind installed capacity in Europe

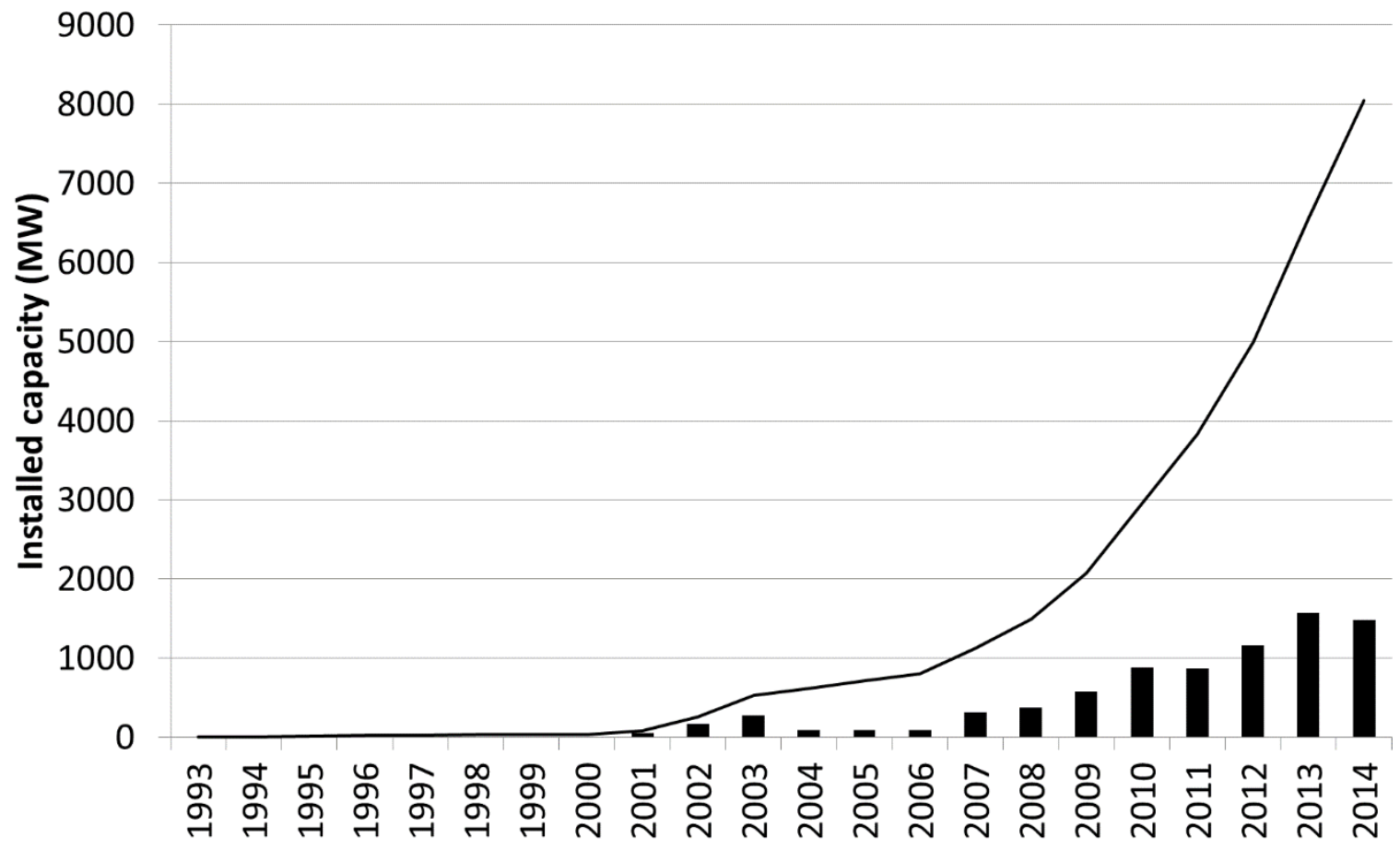

\subsection{Economics of wind farms}

Within an economic framework the evaluation of a construction and implementation of offshore wind farms can be seen from both private and social perspectives.

\subsubsection{Private perspective}

From a private perspective, offshore wind farm benefits are linked to consumer demand for wind energy whereas wind farm costs are those associated with the development of wind farms, which can be classified into initial costs (i.e. construction and connection to the electricity grid) and maintenance costs. These costs are relatively high, especially in cases where the accessibility to the offshore wind farm site is difficult due to severe climatic conditions [12]. Hence, the selection of the site for the development of wind farms is key for the success of the investment of developing a wind farm since such success depends on the wind capacity of the site, which may vary from year to year. Thus, the electricity generation capacity of an offshore wind farm in certain site may be higher than an equivalent wind farm onshore and vice versa. The electricity generation capacity of an offshore wind farm in Greece is up to $40 \%$ higher than an equivalent wind farm onshore since the wind capacity in 
maritime areas is significantly higher than mainland areas, especially in the region of Aegean Sea. Regarding the development and maintenance costs of wind farms offshore wind farms are more expensive than onshore wind farms [14]. However, offshore wind farms development is happening predominantly in European Union Member States due to the expected benefits of higher wind speeds and the lower visual and noise impact [14].

\subsubsection{Social perspective}

From a social viewpoint broader benefits and costs need to be taken into account. Social benefits can be derived from substituting polluting sources of electricity (e.g. fossil fuels, coal) for off-shore wind farms. Such benefits are obtained from reducing environmental impacts associated with energy production derived from polluting sources (i.e. benefits associated with reduction of GHG or costs avoided due to such reduction). The main benefit of wind energy production is that it contributes to GHG emissions abatement and improvement of atmospheric quality $[10,11,17]$. Also, an offshore wind farm can offset up to 2.1 millions of gallons of fresh water per year, as conventional power plants use a large amount of water for their operation [6]. Finally, it has been reported that offshore wind farms could promote ecosystem creation, by operating as artificial reefs [19].

The social costs associated with the development of offshore wind farms are not fully known (e.g. there is not full understanding of its environmental impacts). However, a number of social costs that have been identified include the negative effects of wind farms on ecosystems, visual impact, tourism and noise [6,19-24]. Wind farms could negatively affect the population of marine birds, either through their collision with the turbines or due to the fact that the wind farms could operate as a barrier for their migration [23]. Noise during the construction phase as well as the dredging could cause clogging and damage to early-life stages of several species [24]. Finally, wind farms were found to have visual impact $[20,21]$ and affect negatively to tourist attraction [22].

Other externalities that have been taken into account in the literature relate to job creation. A total of 250,000 working positions associated with offshore wind farms were opened across Europe in 2012 [25]. However, wind turbine installations can also 
be located in traditionally fishery areas, which would cause a loss in their catch for the local fisheries and would be facing their opposition [20]. Furthermore, an offshore wind farm could cause problems in navigation, especially in a busy area like the Aegean, where the transportation between the islands is being made mainly through maritime routes [6].

Therefore, regarding the environmental impacts of wind farms these are site specific as it is the case for the economic impacts. These environmental impacts will depend on the habitats and species that the site is supporting.

We estimate the willingness to pay (WTP) for the development of a hypothetical offshore wind farm located in the Aegean Sea, between the islands of Andros and Tinos, a remote and low populated area. We use a double bound dichotomous choice Contingent Valuation Method (CVM). Furthermore, we investigate the drivers behind respondent's WTP such as individual's base state influences and base state beliefs. This paper contributes to the existing literature in two ways: 1) providing an estimate for the willingness to pay for an offshore wind farm in a remote and low populated location (i.e. estimating the benefits of offshore wind farms in planned locations that minimise negative impacts associated with offshore wind farms); and 2) incorporating into the analysis of WTP for an offshore farm individual's stated behaviour towards the environment and individual's views on climate change and renewable energy along with socio-economic aspects. We include variables such as age groups, gender education and income levels into the analysis of WTP for an offshore farm to control for socio-economic aspects of the respondents. This is the first study, to our knowledge, that incorporates individual's behavioural aspects and views towards the environment, climate change and renewable energy on a WTP study for offshore wind farms. 


\section{Data and methods}

\subsection{Valuation processes of individuals}

In the past few decades, there has been a growing literature on the development of valuation methods to value non-market goods and services as well as on the applications of such methods to a broad spectrum of environmental goods and services. Such applications of existing valuation methods are useful for policy making and project evaluation (e.g. environmental cost-benefit analysis). These valuation methods are based on individual's preferences which can be derived indirectly, through consumption behaviour, or directly, by stating their WTP for an environmental improvement or Willingness to Accept (WTA) compensation for environmental deterioration.

We use a CVM, a stated preference technique, where people are asked to express their WTP contingent to a hypothetical scenario [27]. CVM has been used for the valuation of renewable energy projects and their acceptability by the society [28-30]. Regarding valuation of wind farms in Greece, two economic valuations of an onshore wind farm in Rhodes and South Evia were conducted by [31, 32].

The use of CVM studies to estimate the WTP for green electricity in particular and to protect natural resources in general focuses mainly on the individual behaviour (individual's WTP) and less on the process of such behaviour [33, 34]. Consideration of such processes can be dated back to the work by Fishbein and Ajzen [35, 36]. We use a simplified adaptation of the conceptual model for the valuation process presented in Bateman et al. (2005) [34] (Figure 3). In particular we take into account base-state influences and base-state beliefs in our analysis by using information obtained through the survey. These base state influences and beliefs help to shape individual's attitudes and motives which ultimately determine the individual's behaviour (individual's WTP). 


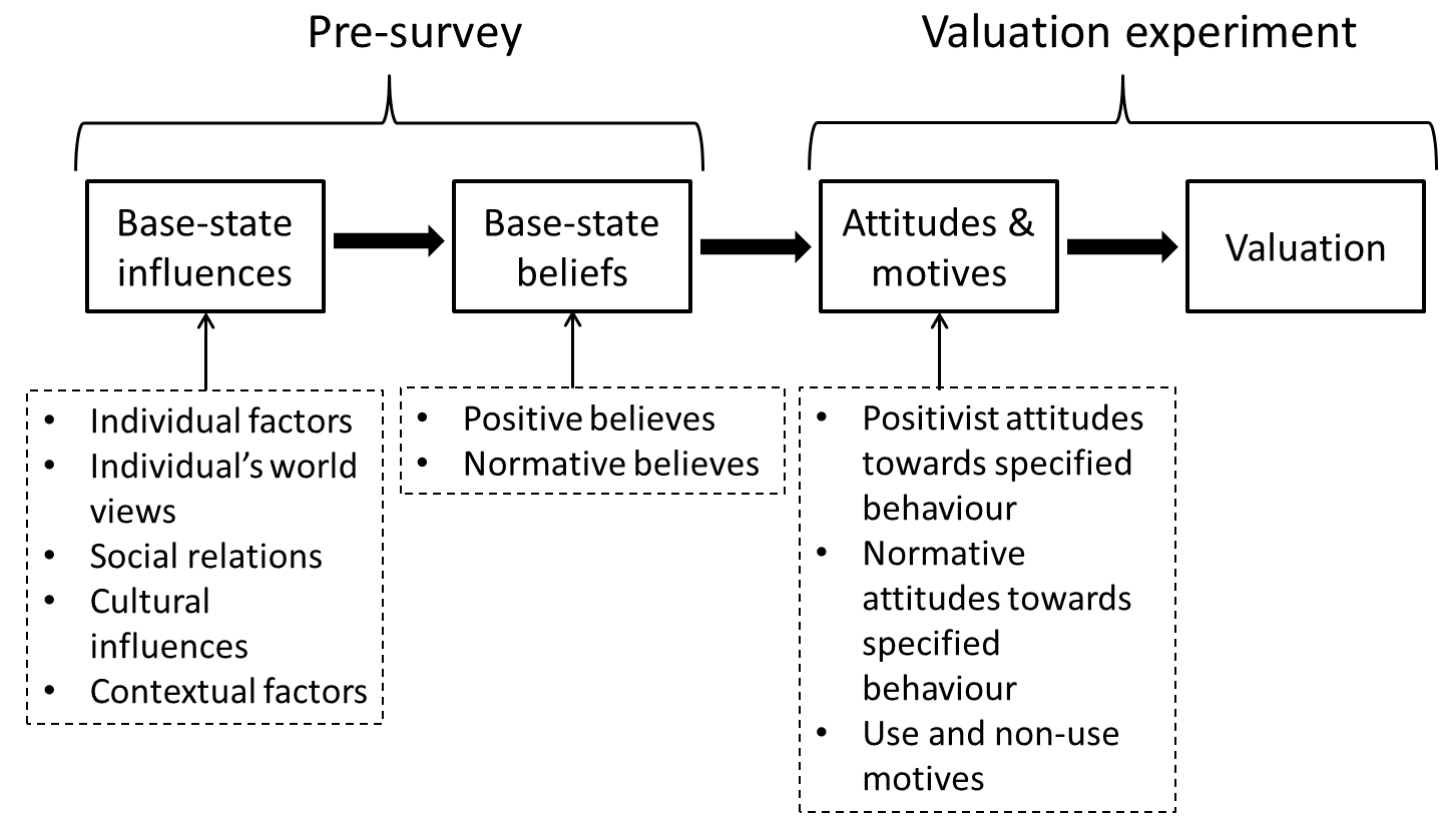

Figure 3. The value formation process

\subsection{The questionnaire}

A total of 141 respondents completed an on-line questionnaire which was used to collect data in a convenience sample of Greek residents (older than 18 years of age). The questionnaire consisted of three sections. The first section included questions regarding respondent's base state influence (i.e. such as individual's world views, individual's environmental behaviour individual factors such as income level and education level) as well as respondent's base state beliefs, which are beliefs regarding consequences of specific behaviour. Regarding individual's base-state influences environmental behaviour respondents were asked about how frequently they use public transport and how frequently they recycle. These aspects were included in our analysis along with socio-economic factors as elements within base-state influences. Regarding base state beliefs we included here statements regarding believes towards climate change and renewable energy sources and wind farms (positive and normative believes). Thus, respondents were also asked to evaluate on a scale from 1 (agree) to 3 (disagree) 11 statements, 7 of them regarding their views on climate change and 4 regarding their views of renewable energy and wind farms (Table 1). The information obtained from the evaluation of statements was used to group participants by their base-state beliefs regarding renewable energy and wind farms using cluster analysis. It is hypothesised that prior beliefs on renewable energy, wind farms and climate change 
may influence individual's willingness to pay for an offshore wind farm. It is therefore hypothesised that individuals who have positive views on renewable energy, wind farms and show concern about the consequents of climate change will be more willing to pay for off shore wind farm development.

Table 1. Statements evaluated by respondents

\begin{tabular}{|c|c|}
\hline & Statement \\
\hline 1 & Climate change is currently occurring (positive belief) \\
\hline 2 & $\begin{array}{l}\text { Climate change is posing a serious threat to the environment (positive believe) } \\
\text { Climate change is occurring due to human impact on the environment (positive } \\
\text { believe) }\end{array}$ \\
\hline 4 & Climate change is occurring due to natural causes (positive belief) \\
\hline 5 & $\begin{array}{l}\text { Climate change should be one of the top priorities in the global policy agenda } \\
\text { (normative belief) }\end{array}$ \\
\hline 6 & $\begin{array}{l}\text { Climate change should be one of the top priorities in the Greek policy agenda } \\
\text { (normative believe) }\end{array}$ \\
\hline 7 & I believe I will be affected by the impacts of climate change (positive believe) \\
\hline 8 & $\begin{array}{l}\text { Renewable energy sources are important for the mitigation of climate change } \\
\text { (positive belief) }\end{array}$ \\
\hline 9 & Wind farms produce renewable energy efficiently (positive belief) \\
\hline 10 & Wind farms are an important source of renewable energy (positive belief) \\
\hline 11 & Wind farms are helping to reduce the impact of climate change (positive believe) \\
\hline
\end{tabular}

In the second section respondents were informed about renewable energy and wind farms as well as the $\mathrm{CO} 2$ and water savings associated with energy being produced by wind farms. They were also informed about the potential construction of the construction of an offshore wind farm in Greece is at the location shown in Figure 4. Participants were presented with the hypothetical scenario of constructing the offshore wind farm in the determined location and were asked for their WTP question for such development taking place: "A possible site for the construction of an offshore wind farm in Greece is at the location below (showing Figure 4) ... The wind farm will be located between the islands of Andros and Tinos, with a $2.75 \mathrm{~km}$ and $4.1 \mathrm{~km}$ distance from the shore respectively. It will have a total capacity of $100 \mathrm{MW}$, which equals to the electricity needed for 40.000 homes. From the generation of the renewable electricity, 160.000 tonnes of CO2 emissions will be avoided and 70-210 million gallons of water will be saved. Renewable energy is currently more costly than that from fossil fuels. 
Therefore consumers are asked to pay a fixed special levy every two months, _through their electricity bill. Are you willing to pay X€?".

We selected the location of the hypothetical offshore farm site based on wind speed and level of tourism development in the area. In order to minimise negative externalities associated with the development of an offshore wind farm a suitable site was considered to be one located in an area with an average high speed throughout the year and with minimal visual impact. We identified 4 islands (Andros, Tinos, Mykonos, Evia which are located in the Aegean Sea and Crete) using a wind atlas by [10]. The chosen location is between the islands of Andros and Tinos, with a $2.75 \mathrm{~km}$ and $4.1 \mathrm{~km}$ distance from the shore respectively (Figure 4). The site is located in a remote area, where both islands are not densely populated (i.e. low visual and noise impact) nor ferry routes pass through that passage. However, the location of the hypothetical wind farm is near a wildlife shelter on the island of Andros, which may raise concerns regarding possible damage to the local fauna. 


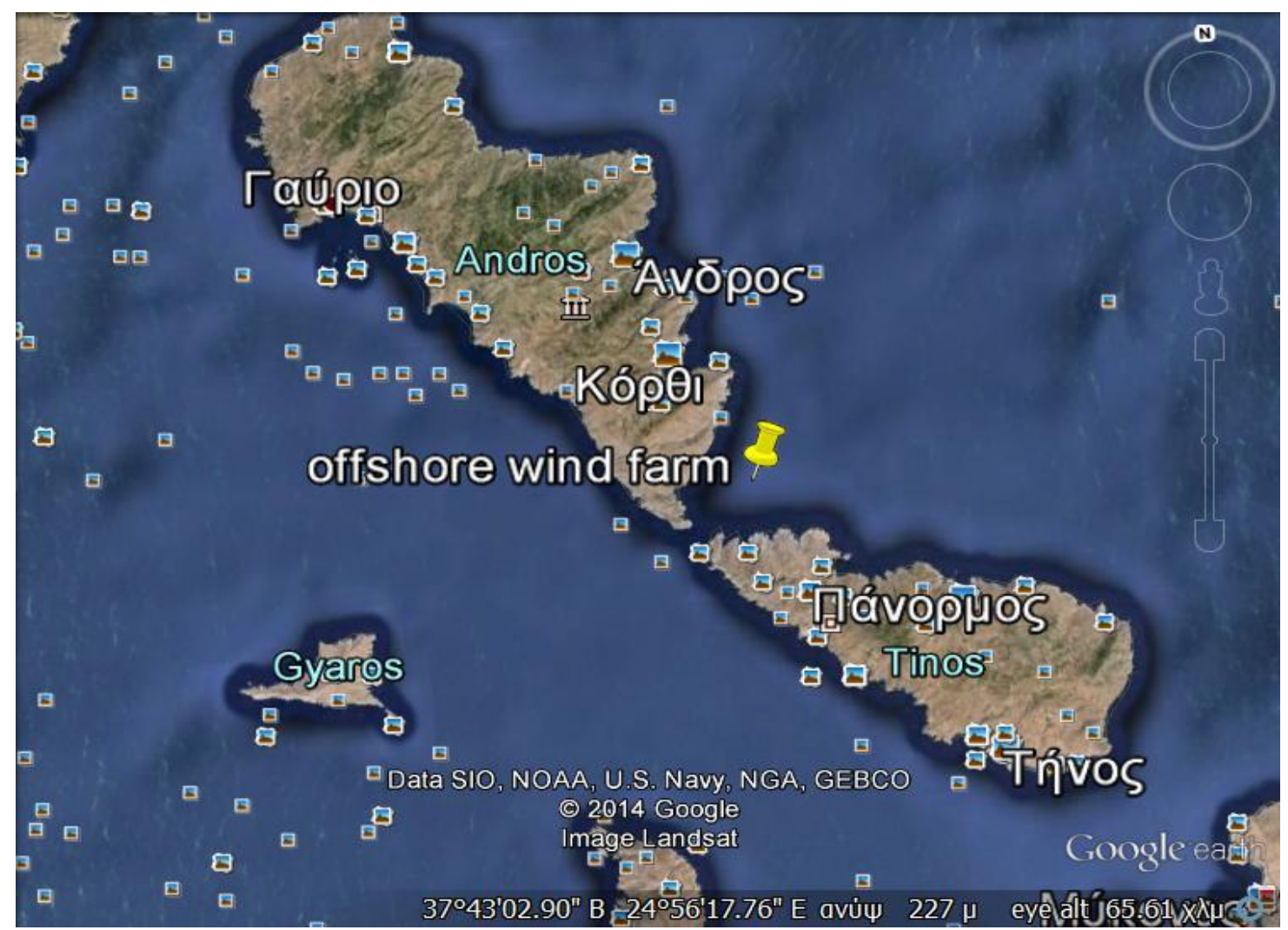

Figure 4. Location of offshore wind farm ${ }^{1}$

We use a double bounded dichotomous choice format to ask participants for their WTP. Thus, participants were asked whether they would be WTP for an initial bid X€. If the respondent answered "yes" ("no), she would be asked whether she would be WTP a higher (lower) amount. The initial bids $(€ 10, € 15, € 20)$ were randomly distributed with follow-ups increasing $(€ 15, € 20, € 25)$ or decreasing $(€ 5, € 10, € 15)$ accordingly ${ }^{2}$. The true WTP is between the lowest amount the respondent declined (upper bound) and the highest amount they accepted (lower bound). Consequently, the respondent's true WTP is not directly observable by the researcher. Finally, the third section included socioeconomic and demographic questions such as age, gender, education level and income (i.e. base-state influences, individual factors).

\footnotetext{
${ }^{1}$ Created on Google Earth

${ }^{2}$ The options for the value of the bid amounts were based on an earlier piloting questionnaire.
} 


\subsection{The statistical analysis: Cluster analysis and econometric model ${ }^{1}$}

We conducted a number of cluster analyses (CA), a statistical method for identifying homogeneous groups, on the statements regarding respondent's positive and normative beliefs on climate change, renewable energy and wind farms. We use a partitioning method ( $k$-means) to group participants into distinct groups according to their views. As a result of CA we obtained 2 groups $(\mathrm{CC} 1$ and $\mathrm{CC} 2)$ regarding respondents' beliefs on climate change and another 2 groups (RE1 and RE2) regarding respondents' beliefs on renewable energy and wind farms. These clusters were incorporated into the econometric model as explanatory variables to investigate the effect of respondent's views on climate change and renewable energy on their WTP for an offshore wind farm. Finally, we included as explanatory variables age groups, gender education and income levels.

According to the random utility model $[33,37]$, the unobserved WTP, following a linear function, is given by

$$
W T P_{i}=c+x_{i}^{\prime} \beta+\varepsilon_{i}
$$

where $c$ is the constant term, $x_{i}$ is the vector of explanatory variables, $\beta$ is the vector of the coefficients, $\varepsilon_{i}$ is the error term, where $\varepsilon_{i} \sim(0, \sigma)$ and $i=1,2,3, \ldots, n$ are the respondents. The lower and the upper bound for each respondent $i$ are denoted by $B_{i}^{L}, B_{i}^{U}$ respectively. Then, the probability of the $W T P_{i}$ being between $B_{i}^{L}$ and $B_{i}^{U}$ is given by

$$
\operatorname{Pr}\left\{W T P i \subseteq\left(B_{i}^{L}, B_{i}^{U}\right)\right\}=\Phi\left(Z_{i}^{L}\right)-\Phi\left(Z_{i}^{U}\right)
$$

where $Z_{i}$ is the standard normal random variable and $\Phi$ is denoted as the standard normal cumulative distribution function (cdf), with $Z_{i}^{U}=\frac{B_{i}^{U}-c-x_{i}^{\prime} \beta}{\sigma}$ and $Z_{i}^{L}=$ $\frac{B_{i}^{L}-c-x_{i}^{\prime} \beta}{\sigma}$. The model is estimated, using interval regression, by maximising the loglikelihood function for the responses which is the following:

\footnotetext{
${ }^{1}$ Cluster and econometric analysis was conducted using Stata Statistical Software: Release 12. College Station, TX: StataCorp LP.
} 


$$
\log L=\sum_{i=1}^{n} \log \left[\Phi\left(Z_{i}^{L}\right)-\Phi\left(Z_{i}^{U}\right)\right]
$$

We use as explanatory variables for WTP respondent's stated base-state influences, their environmental behaviour regarding recycling and frequency of use of public transport; clusters derived from cluster analyses on respondent's positive and normative beliefs on climate change, renewable energy and wind farms (base-state beliefs); base state age, gender, level of education and income. Regarding recycling behaviour a dummy variable (Recycle) behaviour was created taking a value of 1 if the respondent recycles constantly or often and 0 if the respondent recycles rarely or never. Another dummy variable (Public transport) was created taking a value of 1 if the respondent uses public transport always or often and 0 if the respondent uses public transportation rarely or never. 


\section{Results and discussion}

As highlighted above CA was conducted on respondents' evaluation of statements regarding their positive and normative beliefs on climate change, renewable energy and wind farms. These statements and the average score by cluster are shown in Figures 5 and 6. Two clusters per group of statements were obtained. Respondents were classified into two distinct groups regarding their beliefs on climate change. In the first group (CC1) there were those respondents who believe climate change is happening and it is happening due to the human impact on the environment and it should be on the global and Greek government agenda as a top priority; they also believe they will be affected by impacts of climate change. The second group (CC2) was formed by respondents who were less certain about whether climate change is currently happening and their possible causes than respondents belonging to $\mathrm{CC} 1$; those who tend to disagree that climate change should be one of the top Greek government agenda and are uncertain about whether they will be affected by it.

Figure 5. Average evaluation score given to beliefs on climate change by cluster

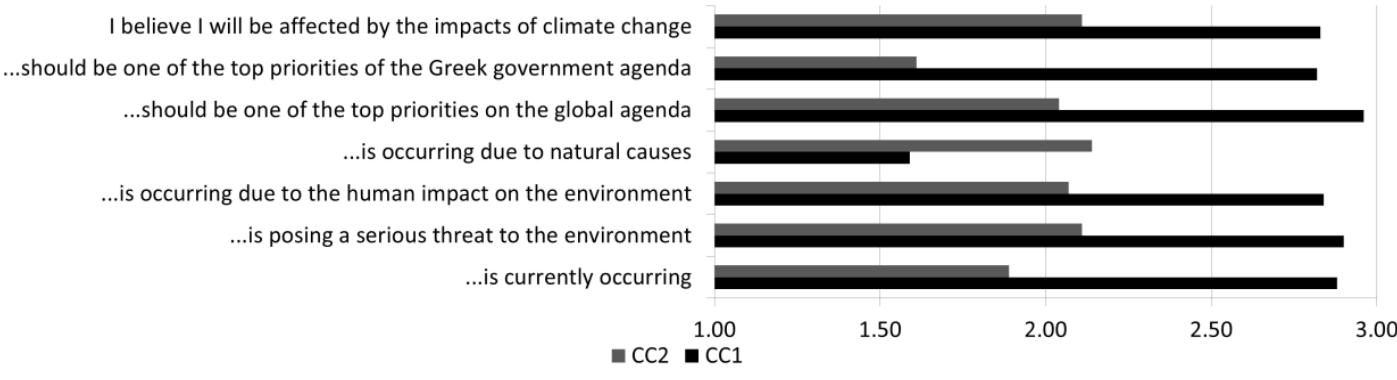

Two groups of respondents were also classified according to respondent's beliefs on renewable energy and wind farms (RE1 and RE2). Although respondents from both groups agreed that renewable energy is important for the mitigation of climate change, respondents belonging to cluster RE1 were more certain about wind farms being an important source of renewable energy which produces energy in an efficient way and can help reducing the impact of climate change. Clustering respondents according to their views on climate change, renewable energy and wind farms serve to incorporate these aspects into the analysis of willingness to pay for an offshore farm. 
Figure 6. Average evaluation score given to beliefs on renewable energy and wind farms by cluster

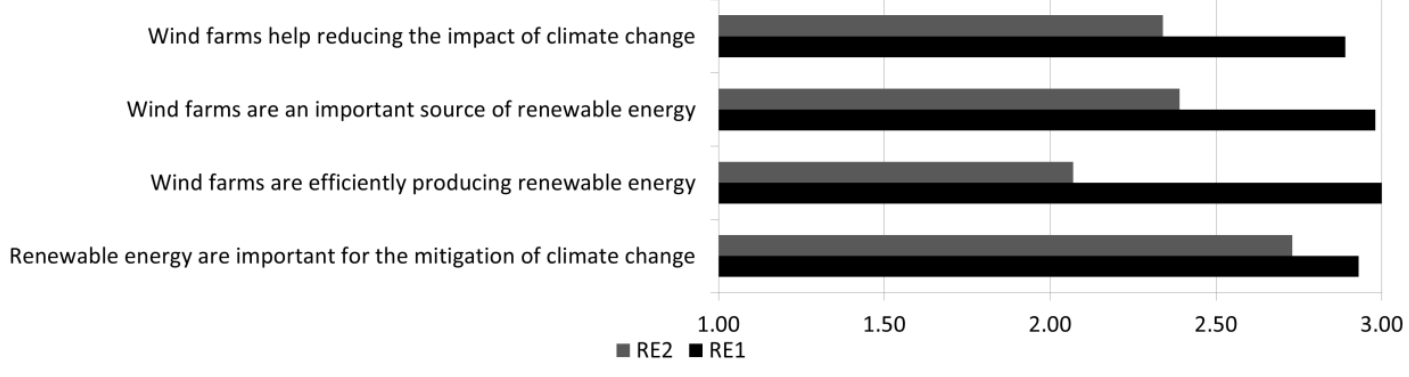

Table 1 and Table 2 present the descriptive statistics of the sample and the results of the interval regression. Regarding respondents' environmental behaviour Table 2 shows that $82.3 \%$ of respondents recycle and $52.5 \%$ use public transport often or always. Taking into consideration respondents views on climate change $79.7 \%$ of respondents belong to cluster $\mathrm{CC} 1$, i.e. cluster formed by respondents who agreed that climate change will affect them and should be on both global and Greek policy agenda since it is happening due to the human impact on the environment whereas $20.3 \%$ belong to cluster $\mathrm{CC} 2$, i.e. cluster formed by respondents who were more sceptical about climate change is occurring or affecting them and disagreed that it should be on the Greek policy agenda. Regarding respondents views on renewable energy and wind farms in particular $68.6 \%$ of respondents were grouped into the RE1 cluster, i.e. cluster formed by respondents who agreed more that wind farms are an important source of producing renewable energy and contribute to reducing the impact of climate change, whereas $31.4 \%$ are of respondents belonging to the RE2 cluster were less certain about whether wind farms are an important source of producing renewable energy and contribute to reducing the impact of climate change. 
Table 2. Descriptive statistics

\begin{tabular}{lcc} 
& Mean & $\begin{array}{c}\text { Standard } \\
\text { deviation }\end{array}$ \\
\hline Recycle (yes=1; no=0) & 0.823 & 0.383 \\
Public transport (yes=1; no=0) & 0.525 & 0.501 \\
Climate change (CC1) & 0.797 & 0.404 \\
Renewable (RE1) & 0.686 & 0.466 \\
Age_26-50 & 0.574 & 0.496 \\
Age_51+ & 0.333 & 0.473 \\
Gender (female) & 0.507 & 0.502 \\
Education (BSc) & 0.411 & 0.494 \\
Education (MSc/PhD) & 0.461 & 0.500 \\
Income (1,000€-2,000€) & 0.347 & 0.478 \\
Income (>2,000€) & 0.270 & 0.445 \\
\hline
\end{tabular}

Results show that base state beliefs are important determinants of individual's WTP for the development of the off-shore wind farm. More specifically it was estimated that respondents belonging to cluster $\mathrm{CC} 1$ and RE1 were WTP $8.88 €$ and $€ 7.41$ more than respondents belonging to cluster CC2 and RE2, respectively. Respondents who believed they will be affected by climate change; that climate change is happening due to the human impact and that climate change should be on the global and government agendas as a top priority were WTP higher amounts than respondents who are uncertain about whether climate change is currently happening. The former were found to be willing to pay $7.41 €$ more than the latter. The views that respondents have on renewable energy and wind farms in particular, i.e. their base state beliefs, determine their WTP. Thus, respondents who think of wind farms as an important source of renewable energy which produces energy in an efficient way helping to reduce the impact of climate change are WTP more than those who are more uncertain about these aspects. Individuals' level of education was found to be a determinant in their WTP with those with higher level of education WTP (BSc, MSc, PhD) being WTP 8-9€ more than respondents with lower levels of education. This is concordance with previous literature which also found positive relation between level of education and willingness to pay for wind farms [36]. We found that age and income level were 
not determining WTP. Finally, female in the sample were WTP 5.35€ more than male for the offshore wind farm.

We also found evidence that base state influences such as respondent's (pre-survey) behaviour towards the environment may determine respondents WTP (Table 3).

Respondents who showed a positive environmental behaviour such as recycling were WTP more than those who do not recycle. However, other environmental behaviour such as the regular use of public transport was not found to be related to the WTP for the development of an offshore wind farm. Although the coefficient associated with respondents using public transport often or always was positive indicating a positive correlation between individual's frequency of use of public transport and individual's WTP this was not found to be statistically significant $(p>0.05)$."

Table 3. Interval regression results: Mean and z-statistic of parameter estimates

\begin{tabular}{lcc} 
& Mean & z-statistic \\
\hline Constant & -0.395 & -0.05 \\
Recycle (yes=1; no=0) & $6.864^{*}$ & 1.81 \\
Public transport (yes=1; no=0) & 1.347 & 0.45 \\
Climate change (CC1) & $8.876^{* *}$ & 2.42 \\
Renewable (RE1) & $7.409^{* *}$ & 2.35 \\
Age_26-50 & 3.248 & 0.58 \\
Age_51+ & 0.894 & 0.15 \\
Gender (female) & $5.346^{*}$ & 1.72 \\
Education (BSc) & $8.823^{*}$ & 1.81 \\
Education (MSc/PhD) & $8.299^{*}$ & 1.73 \\
Income (1,000€-2,000€) & -1.576 & -0.46 \\
Income (>2,000€) & -0.100 & -0.02 \\
\hline & - & \\
Log-Likelihood & 142.235 & \\
$\mathrm{n}$ & 141 & \\
\hline
\end{tabular}

We found that $70.2 \%$ of respondents were willing to pay the first proposed bid and $53.2 \%$ of respondents accepted to pay the second proposed bid. Of the respondents who were willing to pay the first proposed bid $70.7 \%$ were willing to pay a higher bid whereas of the $29.8 \%$ that refuse to pay the first bid $11.9 \%$ were willing to pay a lower amount. Table 4 illustrates the estimated mean and median WTP given the explanatory variables. Respondents would be WTP a premium of $20.37 €$ in their bi-monthly electricity bill for a 100MW wind farm located in between the islands of Andros and 
Tinos. This represents the $0.7 \%$ of their average monthly income, a figure that is within the range of estimates found in previous studies on WTP for renewable energy. The mean WTP for renewable energy varies between $4.60 €^{1}$ and $29.19 €^{2}$ per two months $[26-29,36]$. More specifically in Greece, the mean WTP for a wind power farm in Rhodes (Greece) was estimated to be $8.86 €$ per two months [29] and the mean WTP per two months in South Evia (Greece) was estimated to be $16.13 €$. Compared with this estimate our WTP results are relatively high, in particular regarding results for the Rhodes island. However, two aspects must be beared in mind: 1) whereas respondents in this study were asked for their WTP for an offshore wind farm located in a low populated and remote area, between Andros and Tinos (24 people per $\mathrm{km}^{2}$ and 44 people per $\mathrm{km}^{2}$ in Andros and Tinos respectively) the wind power farm located in Rhodes is in a relatively highly populated area (2,757 per $\left.\mathrm{km}^{2}\right)$; and 2) whereas our respondents were Greek residents (i.e. not local residents from Andros and Tinos) who would not be affected by the negative externalities associated with the offshore wind farm, the sampling frame of the Rhodes project included local individuals who would be affected by the negative externalities associated with wind farms (e.g. visual impact, noise pollution). Therefore, we would expect higher (lower) individual WTP if negative effects associated with wind farms are not (are) present. Previous research has estimated household WTP for offshore wind farms in Denmark being located at long distances from the coast. On this point, locating the wind farms far from the coast minimises their visual and noise impact [22]. It was found that Danish households were WTP between 46 and $122 €$ per year for wind farms to be located $12 \mathrm{~km}$ and $50 \mathrm{~km}$ offshore, respectively, as opposed to having offshore farms at a $8 \mathrm{~km}$ distance [22]. Our results show individual's WTP for an offshore wind farm that minimises its negative effects (i.e. a relatively small population may be affected -visual and noise impact-) from individuals that will not suffer negative impacts. Regarding this point, previous research has not found support for not in my backyard hypothesis [39, 40], however research has focused on individual attitudes towards wind power rather than on the willingness to pay for it. Thus, although respondents living nearby wind power installations may be as likely to have positive attitudes and views towards wind power

\footnotetext{
${ }^{1}$ Mean WTP of 18.5 Chinese yuan, exchange rate 8 Chinese yuan/euro [28]

${ }^{2}$ Mean WTP of 2000 Japanese Yen, exchange rate 137 yen/euro [29]
} 
as people leaving far from wind power stations they may be willing to pay different amounts. Such differences in their willingness to pay are possible and they would reflect the negative effects of wind electricity generation (e.g. visual and noise impact).

Regarding WTP estimates for particular groups of respondents we found that those who recycle and belong to $\mathrm{CC} 1$ and $\mathrm{RE} 1$, with a female with a BSc level of education and belonging to the 26-50 age group would be WTP $38.60 €$ every two months compared to $15.45 €$ which would be the amount that those a female between 26 and 50 years old who do not recycle and do not belong to $\mathrm{CC} 1$ nor RE1, with a BSc level of education would be WTP.

Table 4. Mean and median WTP (€) for offshore wind farm

\begin{tabular}{lll} 
& Mean & Median \\
\hline WTP $(€)$ & 20.37 & 21.56 \\
\hline
\end{tabular}




\section{Conclusion}

We have used a double bounded dichotomous choice contingent valuation method to 1) estimate the willingness to pay for an offshore wind farm located in a low density populated remote area in Greece and 2) investigating the influence of a number of behavioural aspects and views along with socio-economic factors on respondents' willingness to pay.

We found evidence that the development of offshore wind farms in Greece in areas where negative externalities are minimised have public support. Off shore wind energy development was found to be generally supported, especially by highly educated individuals, a result commonly found in the literature [31]. More specifically, 73.7\% of respondents were willing to pay some amount for the offshore wind farm proposed. Hence, there is support for their development as a way to combat potential impacts of climate change. Such development of offshore wind farms would be in line with European Union targets regarding reducing GHG emissions. However, the promotion of offshore wind farms and/or any policy support for the development of offshore wind farm projects is more likely to be backed by the public if offshore farms are located where negative impacts are minimised.

Previous research found developing wind farms to be economically viable with similar support rates as the ones we present here. Our estimates for the willingness to pay for an offshore farm are higher than previous research on the willingness to pay for onshore farms in Greece $[31,32]$. It was found that residents were willing to pay a premium in their bi-monthly electric bill of $€ 8.86$ [29] and $€ 16.13$ [32] for the sole purpose of the construction of the wind farm. Our mean WTP estimate is $€ 20.37$ which differs approximately between $4 €-11 €$ from previous estimates. However, this might partly reflect some of the costs associated with locating wind farms in sites that do not minimise the negative externalities associated with such installations (e.g. visual and noise impact).

Previous studies have analysed people's WTP for wind farms and renewable installations but this is the first study, to the best of our knowledge, which examines how behavioural aspects and views towards the environment, climate change and renewable energy affect individual's willingness to pay for offshore wind farms. We 
found that individual's behaviour and views towards environment, climate change and renewable energy are determinants of their WTP for the offshore wind farm. We found that respondents are WTP $20 €$ in their bi-monthly electricity bill with more environmentally conscious respondents being willing to pay almost $40 €$ and least environmentally conscious approximately $15 €$. This is important from a public policy aspect. Policies aiming at promoting "green energies" such as energy produced from off-shore wind farms may be more likely to succeed if the population is environmentally conscious. Therefore informative/educational activities/programmes in which potential effects of climate change and renewable energy are explained are likely to have an impact on the support for the development of "green energy". 


\section{References}

[1] Fuss S, Daniel JA, Johansson J, Szolgayova M. Obersteiner Impact of climate policy uncertainty on the adoption of electricity generating technologies. Energy Policy 2009;37: 733-43.

[2] Georgakellos DA. Impact of a possible environmental externalities internalisation on energy prices: The case of the greenhouse gases from the Greek electricity sector. Energy Economics 2010; 32: 202-09.

[3] Eurostat. Renewable energy in the EU28 March 2014. http://epp.eurostat.ec.europa.eu/cache/ITY PUBLIC/8-10032014-AP/EN/810032014-AP-EN.PDF

[4] Kottari M. Energy Fact Sheet: Greece. Energy Brains 2014. http://www.energybrains.org/docs/EFS/EnergyBrains_EFS_Greece MK_2014.pdf

[5] YPEKA. Law 3851/2010. YPEKA (Ministry of Environment, Energy and Climate Change) 2010. http://www.ypeka.gr/LinkClick.aspx?fileticket=qtiW90JJLYs\%3d\&tabid=37.

[6] Snyder BK. Ecological and economic cost-benefit analysis of offshore wind energy. Renewable Energy 2009; 34: 1567-78.

[7] Keyaerts N, Delarue E, Rombauts Y, D'haeseleer W. Impact of unpredictable renewables on gas-balancing design in Europe. Applied Energy 2014; 119: 26677.

[8] GWEC. Global Installed Wind Power Capacity. Global Wind Energy Council 2013. http://www.gwec.net/wp-content/uploads/2014/04/5_17-1_globalinstalled-wind-power-capacity_regional-distribution.jpg.

[9] EWEA. The EU wind energy sector skills gap. EWEA 2013. http://www.ewea.org/publications/reports/workers-wanted/

[10] EWEA. The European offshore industry - key trends and statistics 2014. A report by the European Wind Energy Association. 2015

[11] European Environment Agency. Europe's onshore and offshore wind energy potential. An assessment of environmental and economic constraints. Technical report No 6/2009. 2009; pp 90 
[12] Kotroni V, Lagouvardos K, Lykoudis S. High-resolution model-based wind atlas for Greece. Renewable and Sustainable Energy Reviews 2014; 30: 479-89.

[13] Pryor, SC, Barthelmie, RJ. Climate change impacts on wind energy: A review. Renewable and Sustainable Energy Reviews 2010; 14: 430-437.

[14] EWEA. The Economics of wind energy. EWEA 2009.

[15] Perveen R, Kishor N, Mohanty SR. Off-shore wind farm development: Present status and challenges. Renewable and Sustainable Energy Reviews 2014; 29: 78092.

[16] Makarieva AM, Gorshkov VG, Bai-Lian L. Energy budget of the biosphere and civilization: Rethinking environmental security of global renewable and nonrenewable resources. Ecological Complexity 2008;5: 281-288.

[17] Esteban MD, Diez JJ, López JS, Negro V. Why offshore wind energy? Renewable Energy 2011; 36: 444-50.

[18] Lu X, McElroy MB, Nielsen CP, Chen X, Huang J. Optimal integration of offshore wind power for a steadier, environmentally friendlier, supply of electricity in China. Energy Policy 2013; 62: 131-38.

[19] Wilhelmsson D, Malm T, Ohman MC. The influence of offshore windpower on demersal fish. Journal of Marine Science 2006; 79: 775-84 .

[20] O'Keeffe A, Haggett C. An investigation into the potential barriers facing the development of offshore wind energy in Scotland: Case study - Firth of Forth offshore wind farm. Renewable and Sustainable Energy Reviews 2012; 16: 371121.

[21] Ladenburg J, Dubgaard A. Willingness to pay for reduced visual disamenities from offshore wind farms in Denmark. Energy Policy 2007; 35: 4059-71.

[22] Westerberg V, Jacobsen JB, Lifran R. The case for offshore wind farms, artificial reefs and sustainable tourism in the French mediterranean. Tourism Management 2013; 34: 172-83. 
[23] Winiarski KJ, Miller DL, Paton PWC, McWilliams SR. A spatial conservation prioritization approach for protecting marine birds given proposed offshore wind energy development. Biological Conservation 2014; 169: 79-88.

[24] Hammar L, Wikström A, Molander S. Assessing ecological risks of offshore wind power on Kattegat cod. Renewable Energy 2014; 66: 414-424.

[25]EWEA. Wind in power: 2013 European Statistics. European Wind Energy Association 2014. http://www.ewea.org/fileadmin/files/library/publications/statistics/EWEA_Annual _Statistics_2013.pdf.

[26] Perman R, Ma Y, McGilvray J, Common M. Natural Resource and Environmental Economics 201. Pearson Education Limited.

[27] Stigka EK, Paravantis JA, Mihalakakou GK. Social acceptance of renewable energy sources: A review of contingent valuation applications. Renewable and Sustainable Energy Reviews 2014; 32:100-06.

[28] Guo X, Liu H, Mao X, Jin J, Chen D, Cheng S. Willingness to pay for renewable electricity: A contingent valuation study in Beijing, China. Energy Policy 2014; 68: $340-48$.

[29] Nomura N, Akai M. Willingness to pay for green electricity in Japan as estimated through contingent valuation method. Applied Energy 2004; 78: 453-63.

[30] Koundouri P, Kountouris Y, Remoundou K. Valuing a wind farm construction: A contingent valuation study in Greece. Energy Policy 2009; 37: 1939-44.

[31] Mirasgedis S, Tourkolias, C, Tzovla, E, Diakoulaki, D. Valuing the visual impact of wind farms: An application in South Evia, Greece. Renewable and Sustainable Energy Reviews 2014; 39: 296-311

[32] Greene W. Econometric Analysis. 2012 Boston, Mass; London: Pearson, 2012. 
[33] Bateman IJ, Lovett AA, Brainard JS. Applied Environmental Economics. A GIS Approach to Cost-Benefit Analysis. 2005. Cambridge University Press, New York.

[34] Fishbein M, Ajzen I. Belief, attitude, intention, and behavior: An introduction to theory and research. 1975. Addison-Wesley, Reading, Mass

[35] Ajzen I, Fishbein M. Attitude-behaviour relations: A theoretical analysis and review of empirical research. Psychological Bulletin. 1977, 84: 888-918

[36] Shen J. Understanding the determinants of consumers' Willingness to Pay for Eco-Labeled Products: An Empirical Analysis of the China Environmental Label. Journal of Service Science and Management 2012; 5: 87-94.

[37] Zarnikau J. Consumer demand for "Green" power and energy efficiency. Energy Policy 2003; 31: 1661-72.

[38] Zografakis N, Sifaki E, Pagalou M, Nikitaki G, Psarakis V, Tsagarakis, KP. Assessment of public acceptance and willingness to pay for renewable energy sources in Crete. Renewable and Sustainable Energy Reviews 2010; 14: 1088-95.

[39] Ek K. Public and private attitudes towards "green" electricity: the case of Swedish power. Energy Policy 2005; 33: 1677-89.

[40] Wolsink M. Wind power and the NIMBY-myth: institutional capacity and the limited significance of public support. Renewable Energy 2000; 21: 46-64 
